\title{
Occurrence of Metachronous Multiple Malignancies. Review of the Literature: Case of Three Patients
}

Falkenstern Ge RF ${ }^{1 *}$, Kimmich $\mathbf{M}^{1}$, Wohlleber $\mathbf{M}^{1}$, Bode-Erdmann $\mathbf{S}^{2}$, Hüttl K², Grabner A $^{2}$, Friedel $\mathbf{G}^{3}$, Ott $\mathbf{G}^{2}$ and Kohlhäufl $\mathbf{M}^{1}$

${ }^{1}$ Division of Pulmonology, Center for Pulmonology and Thoracic Surgery, Teaching Hospital of the University of Tuebingen, Germany

${ }^{2}$ Department of Clinical Pathology, Teaching Hospital of the University of Tuebingen, Germany

${ }^{3}$ Division of Thoracic Surgery, Center for Pulmonology and Thoracic Surgery, Teaching Hospital of the University of Tuebingen, Germany

\begin{abstract}
We report the rare occurrence of multiple metachronous malignancies in three patients within different time frames from 18 months, 7 years and up to 25 years, respectively.

Multiple primary malignant neoplasias (MPMN) are extremely rare. The key risk factors may be smoking and family history. While numerous studies have been published on the development of secondary malignancies following a first primary, the literature contains only few reports of patients with multiple metachrounous malignancies.
\end{abstract}

Keywords: Multiple primary malignant neoplasms (MPMN); Small cell lung cancer (SCLC); Non-small cell lung cancer (NSCLC); Eastern cooperative oncology group (ECOG); C-reactive protein (CRP); Epidermal growth factor receptor (EGFR)

\section{Case 1: A Patient with Metachronous Triple Malignancies in An Extremely Short Period of 18 Months}

The first patient was a 67 year old non-smoker. He developed three different malignancies in an extremely short period of 18 months. To the best of our knowledge, this report is the first to document the occurrence of triple malignancies in such a short time frame [1].

In August 2012, he was diagnosed with prostate cancer stage pT2c N0 M0 G3 Gleason 7 and underwent radical perineal prostatevesiculectomy. Adjuvant chemotherapy or radiotherapy was not required. Only 10 months later, the patient was diagnosed with basal cell cancer on the skin of his left torso flank; he underwent complete removal of the tumor.

In January 2014, he was again referred to our center due to increasing dyspnea. He was in low clinical state with overall reduced general conditions (ECOG II). Contrast enhanced CT scan revealed a huge tumor mass in the right lower lobe with extensive bilateral pulmonary metastases and pleural carcinosis (Figures 1 and 2). Histological workup of the pleural biopsy revealed infiltration by an adenocarcinoma. Nuclear reactivity of the tumor cells for TTF-1 was well in keeping with the diagnosis of pulmonary adenocarcinoma (Figure 3).

Palliative chemotherapy with carboplatin and pemetrexed was initiated. However, the patient did not tolerate the chemotherapy well. After only 2 cycles of palliative chemotherapy, the treatment was

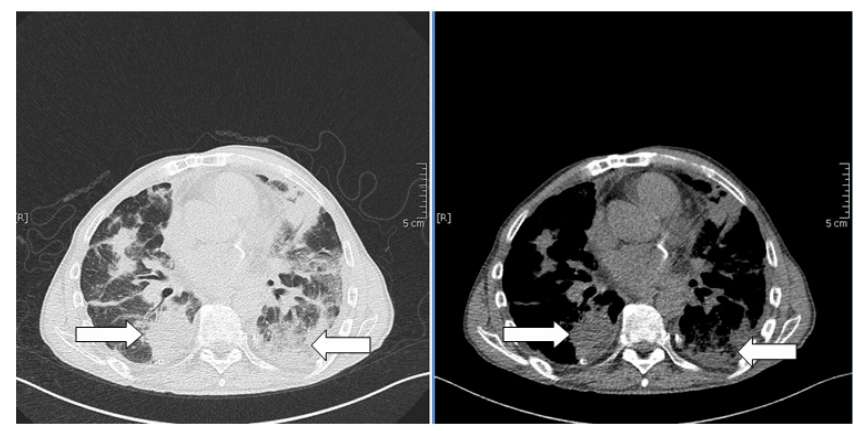

Figure 1: CT- scan revealed a tumor mass in the right lower lobe with extensive bilateral metastases and pleural carcinosis of the left side.

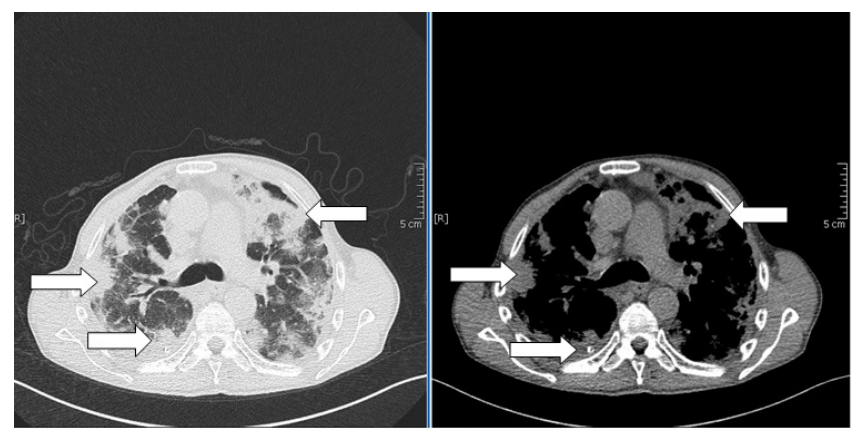

Figure 2: Contrast- enhanced tomography revealed bilateral pulmonary metastases and pleural carcinosis also on the right side.

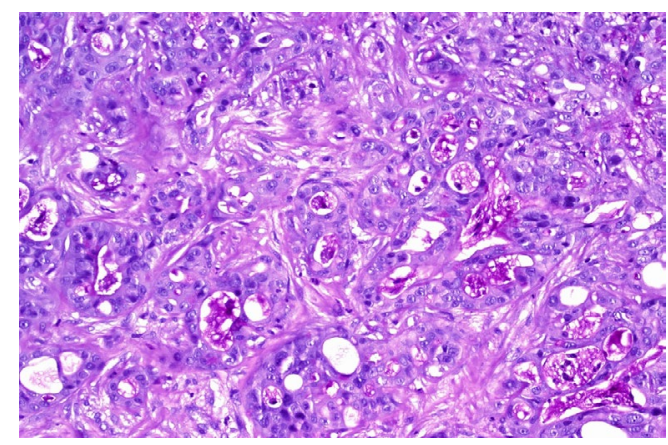

Figure 3: Histological work-up of the pleural biopsy revealed adenocarcinoma (PAS stain, x200). TTF-1 was also positive consistent with pulmonary adenocarcinoma.

*Corresponding author: Falkenstern Ge RF, Division of Pulmonology, Klinik Schillerhoehe, Center for Pulmonology and Thoracic Surgery, Teaching Hospital of the University of Tuebingen, Solitude Str. 18, 70839 Stuttgart- Gerlingen, Germany, Tel: 07156-2030; E-mail: Roger-Fei.Falkenstern-Ge@rbk.de

Received: March 30, 2016; Accepted: April 29, 2016; Published: May 02, 2016

Citation: Falkenstern Ge RF, Kimmich M, Wohlleber M, Bode-Erdmann S, Hüttl $\mathrm{K}$, et al. (2016) Occurrence of Metachronous Multiple Malignancies. Review of the Literature: Case of Three Patients. Oncol Cancer Case Rep 2: 113.

Copyright: (C) 2016 Falkenstern Ge GF, et al. This is an open-access article distributed under the terms of the Creative Commons Attribution License, which permits unrestricted use, distribution, and reproduction in any medium, provided the original author and source are credited. 
Citation: Falkenstern Ge RF, Kimmich M, Wohlleber M, Bode-Erdmann S, Hüttl K, et al. (2016) Occurrence of Metachronous Multiple Malignancies. Review of the Literature: Case of Three Patients. Oncol Cancer Case Rep 2: 113.

stopped. The patient showed prolonged decreased general physical conditions with cancer cachexia. He was directed to supportive care.

\section{Case 2: A Patient with Metachronous Five Malignancies in a 7 years' Time Frame}

The second patient was a 41 year old nonsmoking woman. She suffered from five different tumors; non-small cell pulmonary adenocarcinoma of the lung with multiple osteoplastic metastases in the lumbar spine and along the right ribs, as well as four different malignancies amenable to resection: endometrial adenocarcinoma, chromophobe renal cell carcinoma, bilateral breast cancer, and leiomyosarcoma of the right thigh $[2,3]$.

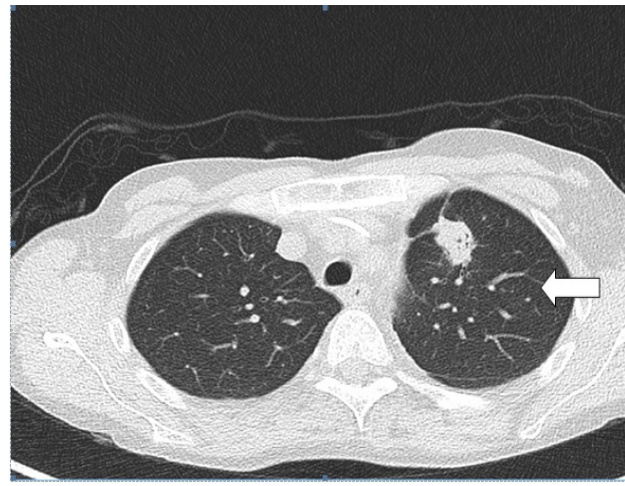

Figure 4: Contrast- enhanced tomography revealed a major pulmonary mass of left upper lobe (arrow).

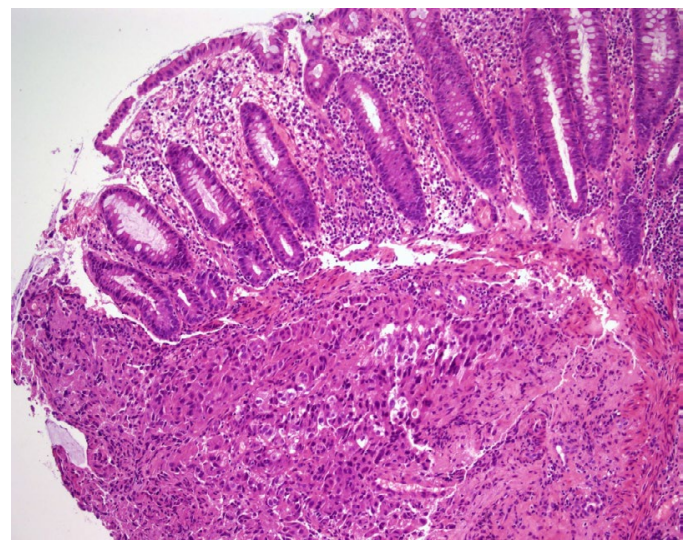

Figure 5: Demonstrates colonic metastasis by endometrial cancer undermining in part intact overlying mucosa. The tumor cells expressed PAX8 and were negative for TTF1 (H\&E x100).

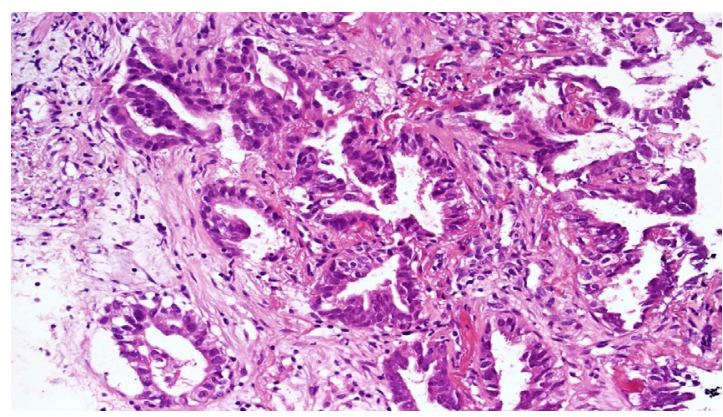

Figure 6: Shows infiltrating acinar adenocarcinoma in a transbronchial biopsy of the lung. The tumor cells were positive for TTF1 (H\&E x200).

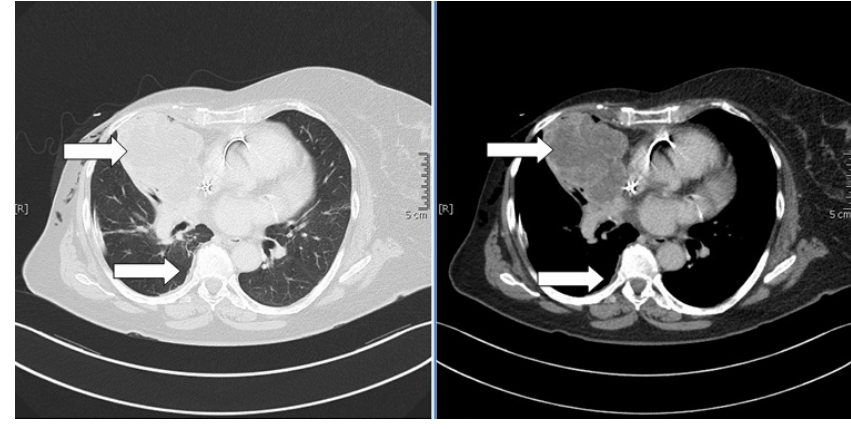

Figure 7: Contrast- enhanced tomography revealed a huge pulmonary mass within the right upper and middle lobe (arrow), Pleural carcinomatosis at the right side (Figure $7 \mathrm{a}$ and $7 \mathrm{~b}$ ).

The patient had a long history of different malignancies. In 2006, she developed a lump in the right breast, for which she underwent lumpectomy with axillary clearance. Histopathology showed early infiltrating ductal carcinoma, stage pT2 N0 M0. She underwent mastectomy and postoperative adjuvant radiotherapy to the breast and regional lymph nodes. In 2007, she developed another lump in the left breast, with histopathology revealing ductal carcinoma of the breast. She underwent mastectomy and postoperative adjuvant radiotherapy to the remaining area of the left side. A therapy with tamoxifen for 5 more years was initiated.

In 2007, she was also diagnosed with endometrial adenocarcinoma metastasizing to the colonic mucosa (Figure 5). Radical hysterectomy was performed.

In 2011, she was diagnosed with chromophobe renal cell carcinoma of the left kidney. Due to the small size, it could be totally removed through segmental wedge resection. No radiotherapy or adjuvant chemotherapy was needed.

In 2012, a mass on the right upper thigh without osseous infiltration was noted, and histology revealed leiomyosarcoma.

In 2013, she was referred to our center due to slight exertional dyspnea with weight loss. The CT scan revealed a pulmonary mass of the left upper lobe (Figures 4 and 5). Staging examination revealed multiple osteoplastic osseous metastases of the lumbar spine and right side ribs. Transbronchial biopsy revealed pulmonary adenocarcinoma (Figure 6)

Since EGFR mutation was detected, systemic therapy with erlotinib (Tarceva) with $150 \mathrm{mg}$ daily dose was initiated.

\section{Case3:A Patient with Metachronous Quadruple Malignancies in a Time Frame of 25 years}

The third patient was a 73 year old smoking woman with a history of 40 pack years [4-6]. Four malignancies were diagnosed within 25 years $[7,8]$. Small cell carcinoma of the lung, basal cell cancer on the skin of the right cheek, papillary thyroid carcinoma of the left lobe and breast cancer of the right breast [9-13].

In 1989, the patient developed a lump in the right breast, for which she underwent lumpectomy with axillary clearance. Histopathology showed infiltrating ductal carcinoma, stage pT2 N0 M0. She underwent mastectomy and postoperative adjuvant radiotherapy to the breast and regional lymph nodes, followed by therapy with tamoxifen for 5 years. In 1990, the patient had the subjective feeling of a lump in her throat. A thyroidal mass was detected in the left thyroid lobe. Upon biopsy, the 
Citation: Falkenstern Ge RF, Kimmich M, Wohlleber M, Bode-Erdmann S, Hüttl K, et al. (2016) Occurrence of Metachronous Multiple Malignancies. Review of the Literature: Case of Three Patients. Oncol Cancer Case Rep 2: 113.

Page 3 of 3

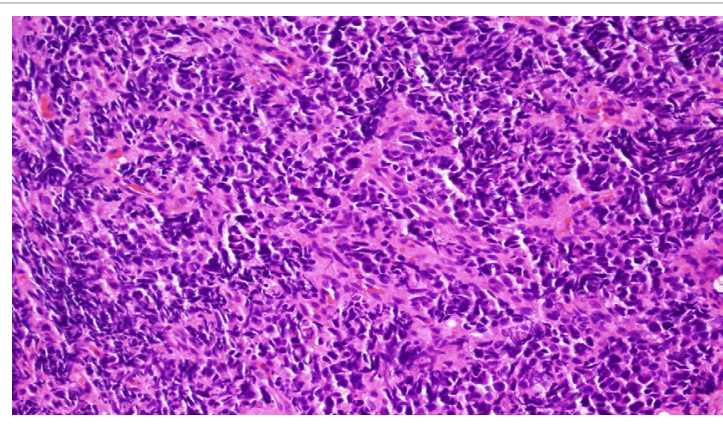

Figure 8: Histological work-up of a pleural biopsy showed small cell carcinoma with characteristic crush artifacts (H\&E x200).

histology revealed papillary thyroid carcinoma of the left lobe pT2 N0 M0. She underwent total thyroidectomy with resection of both thyroid lobes.

In 2010, the patient was diagnosed with basal cell carcinoma on her right cheek; she underwent excision of with complete removal of the tumor.

In 2013, she was referred to our center due to a large pleural effusion on the right side. Due to her severe dyspnea, we performed pleural drainage on the right side. The CT scan revealed a huge mass which filled the right upper/middle lobes (Figure 7). Cytological work up revealed tumor cells of a small cell carcinoma in the pleural effusion, and pleural biopsy confirmed the diagnosis (Figure 8).

Systemic chemotherapy with cisplatin and etoposid was initiated. Due to severe tumor progression and further decreased clinical conditions, our patient was also later directed to best supportive care in hospice.

\section{Discussion}

We report the rare occurrence of multiple malignancies in three patients within different time frames from 18 months, 7 years and up to 25 years, respectively.

\section{References}

1. Renda A, Carlomagno N (2009) Nosography. Multiple Primary Malignancies. Springer-Verlag, Italy.

2. Warren S, Gates O (1932) Multiple primary malignant tumors: a survey of the literature and statistical study. Am J Cancer 16: 1358-1414.

3. Yamasaki M, Higuchi M (1970) An autopsy case of synchronous quadruple cancer. Strahlentherapie 140: 275-279.

4. Angurana SL, Kapoor R, Kumar P, Khosla D, Kumar N, et al. (2010) Quadruple malignancy in a single patient: a case report and comprehensive review of literature. J Cancer Res Ther 6: 230-232.

5. Engeland A, Bjørge T, Haldorsen T, Tretli S (1997) Use of multiple primary cancers to indicate associations between smoking and cancer incidence: an analysis of 500,000 cancer cases diagnosed in Norway during 1953-1993. In J Cancer 70: 401-407.

6. Mussari S, Amichetti M, Tomio L (2000) Quadruple cancer in a single patient: a report of four cases. Eur J Surg Oncol 26: 614-616.

7. Slaughter DP, Southwick HW, Smejkal W (1953) Field cancerization in ora stratified squamous epithelium; clinical implications of multicentric origins. Cancer 6: 963-968.

8. Huang XY, Huang ZL, Huang J, Zhi-Gang W, Qi Z, et al. (2012) A case of multiple primary malignancies and investigation of family history. Oncology Letters 4: 931-934.

9. Spratt JS Jr, Hoag MG (1966) Incidence of multiple primary cancers per manyear of follow up: 20-year review from the Ellis Fischel State Cancer Hospital. Ann Surg 164: 775-784.

10. Schottenfeld D (1996) Cancer Cancer Epidemiology and Prevention, New York: Oxford University Press.

11. Fischer B, Costantino JP, Redmond CK, Fisher ER, Wickerham DL, et al. (1994) Endometrial cancer in tamoxifen-treated breast cancer patients: Findings from the National Surgical Adjuvant Breast and Bowel Project (NSABP) B-14. J Nat Cancer Inst 86: 527-537.

12. Rutqvist LE, Johansson $H$, Signomklao $T$, Johansson $U$, Fornander $\mathrm{T}$, et al (1995) Adjuvant tamoxifen therapy for early stage breast cancer and second primary malignancies. J Natl Cancer Inst 87: 645-651.

13. Zhou C, Wu YL, Chen G, Feng J, Liu XQ et al. (2011) Erlotinib versus chemotherapy as first-line treatment for patients with advanced EGFR mutationpositive non-small-cell lung cancer (OPTIMAL, CTONG-0802): a multicentre open-label, randomised, phase 3 study. Lancet oncology 12: 735-742. 